\title{
Differentiating Between Lactose Intolerance, Celiac Disease, and Irritable Bowel Syndrome-Diarrhea
}

Karlen E. (Beth) Luthy

Brigham Young University - Provo, beth_luthy@byu.edu

Sophia G. Larimer

Donna S. Freeborn

Brigham Young University - Provo

Follow this and additional works at: https://scholarsarchive.byu.edu/facpub

Part of the Other Nursing Commons

\section{Original Publication Citation}

Luthy, K. E., Larimer, S. G.**, \& Freeborn, D. S. (2017). Differentiating between lactose intolerance, celiac disease, and irritable bowel syndrome-diarrhea. The Journal for Nurse Practitioners, 13(5), 348-353.

\section{BYU ScholarsArchive Citation}

Luthy, Karlen E. (Beth); Larimer, Sophia G.; and Freeborn, Donna S., "Differentiating Between Lactose Intolerance, Celiac Disease, and Irritable Bowel Syndrome-Diarrhea" (2017). Faculty Publications. 5247. https://scholarsarchive.byu.edu/facpub/5247 


\title{
Differentiating Between Lactose
}

\section{Intolerance, Celiac Disease, and Irritable Bowel Syndrome-Diarrhea}

Karlen E. Luthy, DNP, FNP, Sophia G. Larimer, MS, FNP, and

Donna S. Freeborn, PhD, FNP

\begin{abstract}
The purpose of this article is to assist nurse practitioners (NPs) and other primary care providers in differentiating between lactose intolerance, celiac disease, and diarrheapredominant irritable bowel syndrome in adults. Based on subtle characteristics gathered from the history and physical examination, the NP's examination and approach to testing will help distinguish between the 3 conditions. NPs should use a sequential process of examination and testing to distinguish gastrointestinal disorders that share common symptoms. A best practice algorithm is provided.

Keywords: abdominal pain, celiac disease, diagnosis, irritable bowel syndrome, lactose intolerance

(C) 2017 Elsevier Inc. All rights reserved.
\end{abstract}

\section{INTRODUCTION}

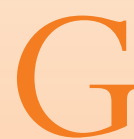
astrointestinal (GI) disorders are frequently seen in primary care settings and commonly include lactose intolerance (LI), celiac disease (CD), and irritable bowel syndrome (IBS). However, these disorders are often difficult to differentiate because each condition shares common symptoms, which can contribute to delay in diagnosis. In fact, it takes approximately 1 year for patients with CD to be diagnosed after GI symptoms appear. ${ }^{1}$ Likewise, $10 \%-15 \%$ of the population in the United States is affected by IBS, but only 5\%-7\% are actually diagnosed, ${ }^{2}$ and usually only after their primary care provider has referred them to a gastroenterologist.

Abdominal complaints are commonly seen in the primary care setting; therefore, nurse practitioners (NPs) must be well versed in GI-related disorders and utilize evidence-based information to work through various differential diagnoses. Although LI, CD, and IBS may present with similar symptoms, the pathology differs. Unlike primary LI and IBS-D, which mainly cause symptoms without mucosal inflammation, if CD is not properly diagnosed, GI mucosal inflammation will continue, which may result in poor growth, nutritional deficiencies, and other further complications. According to Pironti et $\mathrm{al}^{4}{ }^{4}$ among patients complaining of chronic diarrhea and/or abdominal pain, $81 \%$ have microscopic histologic damage due to an underlying pathologic process. Therefore, it is imperative that NPs use the most current information to make accurate and timely diagnoses to prevent pathologic disease processes from ensuing and to improve the patient's quality of life. ${ }^{5,6}$ Accordingly, the purpose of this article is to introduce NPs to a systematic evidence-based approach for successfully differentiating LI, CD, and IBS in adults.

\section{BACKGROUND INFORMATION ON LI, CD, AND IBS}

\section{Lactose Intolerance}

LI is the most common metabolic food sensitivity, affecting $60 \%-70 \%$ of people worldwide. Inadequate levels of the lactase enzyme result in abdominal discomfort, bloating, gas, and diarrhea, because undigested lactose in the colon is fermented by bacteria. 7,9 Primary lactose deficiency is the most common cause of LI and is found most frequently in South America, Africa, Asia, and descendants from 
those areas. Secondary lactose deficiency results from injury and inflammation of the brush border of the small intestine, such as can be found in Crohn's disease, and can also be caused by bacterial overgrowth, gastroenteritis, $\mathrm{CD}$, and disorders that cause rapid GI motility. ${ }^{7,10}$

LI usually begins in childhood, but it is most prevalent in adulthood, because the lactase enzyme progressively decreases over the lifespan. ${ }^{8,9,11}$ About two thirds of people in the world do not carry the genetic makeup that allows for lactase production, and are therefore either lactase persistent or nonpersistent. $^{12}$

\section{Celiac Disease}

$\mathrm{CD}$ is a genetically or autoimmune-based chronic enteropathy of the small intestine that is caused by an intolerance to gluten. ${ }^{5}$ Gluten is a complex of watersoluble protein that is a component in wheat, barley, bulgur, durum, rye, and spelt. ${ }^{5}$ People who have the genetic predisposition for CD typically carry the human leukocyte antigen (HLA)-DQ2 or HLADQ8 genes (90\% and 10\%, respectively). ${ }^{5,6}$ Patients with genetic-based and autoimmune diseases (especially Turner's syndrome, Down's syndrome, type I diabetes mellitus, and thyroid disease), as well as first-degree relatives of patients with $\mathrm{CD}$, are considered to be high risk for developing $\mathrm{CD} .{ }^{5,6} \mathrm{An}$ autoimmune process proceeds when class II HLAs produce autoantibodies against the enzyme tissue transglutaminase (tTG) in the presence of gluten, damaging the small intestine and altering the environment in which nutrients are absorbed. ${ }^{5}$ Although many patients can be managed simply by excluding gluten from the diet, a few patients may require more aggressive treatment with immunomodulatory medications. $^{3}$

CD involves a variety of symptoms with both GI and systemic manifestations, usually lasting longer than 3 months. A patient typically presents with diarrhea, unexplained weight loss, abdominal distention, bloating, dyspepsia, and flatulence. ${ }^{5}$ It is not uncommon for pain to be specifically located in the right lower abdomen, and even accompanied by a palpable mass, raising suspicions of appendicitis or Crohn's disease. ${ }^{13}$ Systemic manifestations of CD include migraines, chronic fatigue, depression, irritability, Duhring's dermatitis herpetiformis, oral aphthous ulcers, loss of dental enamel, irondeficiency anemia, anorexia, osteoporosis, joint pain, growth failure, short stature, delayed puberty, amenorrhea, early menopause, reduced fertility, and epilepsy. ${ }^{6,9,14}$ In addition to systemic manifestations, patients with CD also have a 3-fold increased risk of non-Hodgkin's lymphoma. ${ }^{6}$

\section{Irritable Bowel Syndrome}

IBS affects $10 \%-15 \%$ of the world's population and is a set of GI symptoms resulting from irregular relaxation and contraction of the bowel. ${ }^{2}$ The idea that there may be a connection between excessive microflora in the gut, as well as excessive inflammation and cytokine activity, is supported by evidence. ${ }^{15}$ Basic risk factors for IBS include female gender; being between 20 and 40 years old; and having psychosocial issues, such as anxiety, depression, personality disorders, and abuse. ${ }^{16}$ There are 4 subtypes of IBS, but IBS with diarrhea (IBS-D) is most often confused with CD and LI. Patients with IBS-D typically report diarrhea and abdominal cramping that mainly occurs in the mornings and after meals. Other complaints include mucus in the stool, fecal incontinence, feelings of incomplete evacuation, and pain relieved by defecation. ${ }^{10,15}$ IBS-D does not cause permanent damage to the colon or increase the risk for colorectal cancer, although it does severely impact a patient's quality of life. There is a possibility that CD and IBS-D can coexist, but there are conflicting results supporting routine screening of these concurrently. .,17 $^{3,17}$

\section{CURRENT RECOMMENDATIONS FOR DIAGNOSING LI}

According to the most current information, it is sufficient to diagnose a patient with LI if GI complaints resolve with a lactose-free diet for at least 2 weeks. However, if symptoms persist or if the patient is unsuccessful or refuses to adhere to a trial of lactose elimination, he or she should undergo the lactose hydrogen breath test (sensitivity [69\%-100\%] and specificity [89\%-100\%]), which is noninvasive and cost-effective. During the test, individuals are given $2 \mathrm{~g} / \mathrm{kg}$ of lactose and tested for hydrogen in their breath at a fasting baseline and in 30-minute intervals for 3 hours. ${ }^{8,10}$ False-positive results occur 
with inadequate pretest fasting or recent smoking, and false-negative results occur with antibiotic use, diabetes, gastric-emptying issues, or underlying pulmonary disorders, because these factors can affect the amount of hydrogen levels detected in the breath of patients. ${ }^{7}$ An alternative option to the lactose hydrogen breath test is the lactose tolerance test, although it has a lower sensitivity (77\%-96\%) and specificity (76\%-94\%) and is less convenient for the patient because it requires consecutive blood sampling. ${ }^{11}$

A patient who has a negative lactose hydrogen breath test or lactose tolerance test but continues to display abnormal GI symptoms after consuming lactose may opt to undergo genetic testing or a biopsy-based lactose intolerance quick test, which has a sensitivity, specificity, and positive predictive value nearing 100\%. The biopsy sample can be collected during endoscopy; however, because of its high cost and invasiveness, the NP should order endoscopy conservatively. Although genetic testing of the $\mathrm{C} / \mathrm{C}$ $(-13910)$ and $\mathrm{T} / \mathrm{C}(-13910)$ genes is an alternative option, it is also costly and should be utilized conservatively. ${ }^{7,8,11}$

\section{CURRENT RECOMMENDATIONS FOR DIAGNOSING CD}

\section{Serologic Testing}

Diagnosis of CD first begins with serologic screening for antibodies. ${ }^{18}$ The first-line serologic test is the tissue transglutaminase antibody (IgA tTG), which has high sensitivity (90\%-98\%) and specificity (95\%-97\%), is inexpensive, reliable, and easy to interpret. According to evidence-based information, a "total IgA" level should be tested simultaneously, because $2 \%$ of people with CD have an IgA deficiency and, therefore, may falsely test negative for IgA tTG. Patients who have an IgA deficiency should next be tested for the IgG anti-deaminated gliadin peptide serum antibody and the IgG tissue transglutaminase antibody (IgG tTG). ${ }^{5}$

It is imperative that patients are on a gluten-rich diet at the time of lab work because the absence of gluten in the diet may result in a false-negative test. Patients who cannot commit to eating a gluten-rich diet prior to CD testing may have false-negative tests, but can be screened via the $\operatorname{IgA}$ tTG, total $\operatorname{IgA}$, and IgG anti-deaminated gliadin peptide, and, if positive, can proceed to upper endoscopy with small bowel biopsy. If the patient is on a gluten-free diet and their serology tests are negative, they can be screened for HLA-DQ2/DQ8 genes. If these genetic markers are negative, it is very unlikely the patient has CD. ${ }^{5,19}$ However, a positive HLA-DQ2/DQ8 cannot be used as a stand-alone test to reliably and definitively diagnose CD. ${ }^{20}$

\section{Endoscopy}

If serology is positive, or if there is a high probability of $\mathrm{CD}$, patients should be referred to a gastroenterologist for an upper endoscopy and small bowel biopsy. Samples obtained during endoscopy are graded according to the Marsh criteria, which categorize the severity of the patchy, inflamed lesions of the small bowel. Currently, debate exists regarding other noninvasive approaches to confirm CD, but endoscopy with biopsy is considered the "gold standard" for diagnosis. 5,6

\section{Alternative Testing for CD}

Current trends include the use of alternative, lessinvasive methods to rule-out $\mathrm{CD}$, especially for the elderly and high-risk populations who may not tolerate endoscopy. Capsule endoscopy, where an encapsulated camera is ingested and passed through the GI tract, may be ordered as an alternative if the patient refuses endoscopy and no alarm symptoms are present. However, it should be noted that the small bowel capsule does not provide definitive histology for diagnosis. Another option, although not the preferred method, is to use a combination of antibody titers to predict the amount of damage caused to the small intestine. Tortora et $\mathrm{al}^{18}$ found that the presence of tTG levels $(>62.4 \mathrm{U} / \mathrm{mL})$ accompanied by elevated anti-endomysial antibody levels $(>45$ $\mathrm{U} / \mathrm{mL}$ ) were diagnostic for small bowel damage.

\section{CURRENT RECOMMENDATIONS FOR DIAGNOSING} IBS-D

Traditionally, there have been no specific tests that directly detect IBS-D; the diagnosis has been assigned only after ruling out other diseases. ${ }^{3}$ Essentially, the patient's specific clinical history and background dictates the provider's approach to testing. For cases of chronic diarrhea (lasting longer than 2-4 weeks), 
the most basic serologic tests should include a complete blood count, C-reactive protein, and CD serology. ${ }^{16}$ Additional tests include stool studies, such as cultures, ova and parasites, giardia, and/or Clostridium difficile, especially if the patient has recently traveled abroad or has been hospitalized. ${ }^{2}$

Two new IBS-D diagnostic tools are now available to the NP: (1) the newly updated Rome IV criteria; and (2) the IBSchek ${ }^{\mathrm{TM}}$ (Commonwealth Laboratories LLC). The Rome IV criteria, introduced in May 2016, can be used to substantiate a diagnosis IBS-D. The ROME IV includes questions regarding the presence of recurrent abdominal pain for at least 1 day/week in the last 3 months that is associated with 2 or more of the following: defecation; a change in frequency of stool; and a change in stool consistency. A positive Rome IV screening has a sensitivity of $62.7 \%$ and a $97.1 \%$ specificity. ${ }^{21}$ The IBSchek $^{\mathrm{TM}}$ was approved by the United States Food and Drug Administration for use in 2015 and is an enzyme-linked immunoassay-based serum test that is predictive of IBS-D based on the presence of 1 or 2 antibodies: anti-cytolethal distending toxin $\mathrm{B}$ and anti-vinculin. ${ }^{22}$ Currently, only 1 study has been published regarding the accuracy of IBSchek ${ }^{\mathrm{TM}} \cdot 23$ With elevated anti-cytolethal distending toxin B, the specificity and sensitivity for IBS-D are $91.6 \%$ and $43.7 \%$, respectively. An elevated anti-viniculin is $83.8 \%$ specific and $32.6 \%$ sensitive for IBS-D. ${ }^{23}$ Because of the lack of data on IBSchek ${ }^{\mathrm{TM}}$, some researchers still recommend using symptom-based criteria, such as the Rome IV, for diagnosis of IBS-D. ${ }^{24}$

Figure. Algorithm to differentiate LI, CD, and IBS-D.

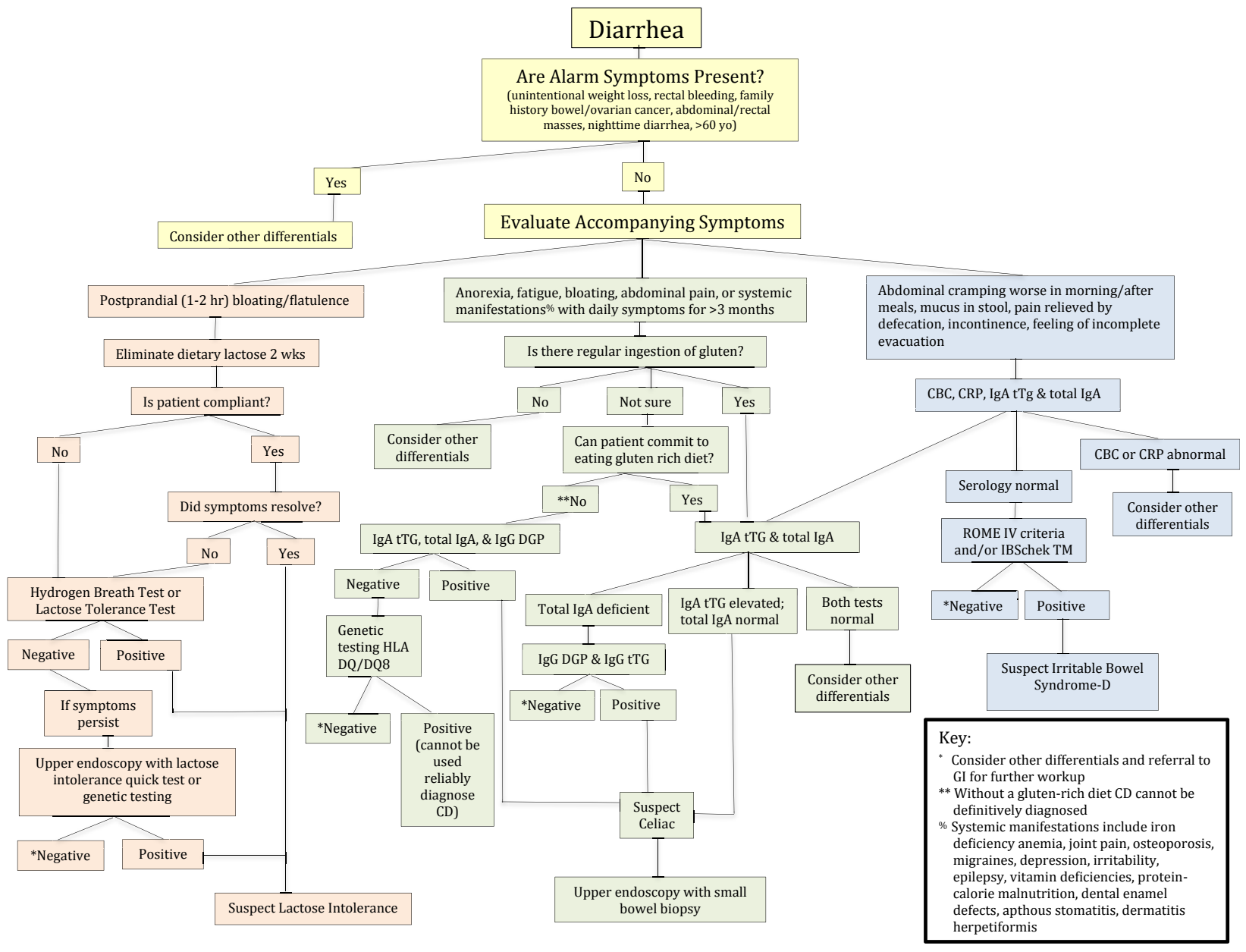




\section{DISCUSSION}

Complaints of abdominal pain, bloating, gas, and diarrhea are often present in LI, CD, and IBS-D and contribute to a delay in diagnosis. For example, ordering a series of stool studies is appropriate if the patient has recently traveled internationally, recently taken antibiotics, or has been hospitalized. Likewise, when CD is the top differential, it is crucial that the NP screens for a family history of CD and other autoimmune diseases. When IBS-D is highly suspected, at the very least a complete blood count, C-reactive protein, and CD serology should be undertaken.

\section{Limitations}

There are limitations to our literature review, some of which are attributable to the fact that a portion of the information was gathered from studies performed in other countries. LI, CD, and IBS-D each have an effect on specific international populations, and synthesizing data into 1 composition of evidence could influence the results. Many of the studies that were pertinent to LI involved patients of Asian descent. The majority of these studies were performed on adults, 18-75 years old, so best practice recommendations may not be as valuable in assisting NPs in addressing GI issues in the pediatric population.

\section{CONCLUSION}

LI, CD, and IBS-D present with similar symptoms, which can be misleading and contribute to a delay in diagnosis. The NP must be exceptionally thorough in obtaining the patient's history and performing the physical exam in order to identify subtle clues that could lead to the correct diagnosis. The patient's age, ethnicity, gender, family history, psychosocial history, recent travel and hospitalization, diet, and timing of symptoms should be considered. It is critical that patients with alarm symptoms (fatigue, weight loss, nocturnal diarrhea, and blood in the stool) are referred to gastroenterology for more aggressive testing, which likely involves endoscopy. The NP can use the provided algorithm (see Figure) when he or she encounters patients presenting with symptoms of abdominal pain, bloating, gas, and diarrhea. However, the NP should also consider other differentials and order additional testing that would be appropriate for the individual's presentation. Therefore, it is critical for NPs to be prepared with a process to distinguish bowel disorders, prioritize differential diagnosis, and order appropriate tests that can guide them in their diagnosis of LI, CD and IBS-D with the goal of improving the quality of life of patients.

\section{References}

1. Fuchs V, Kurppa K, Huhtala H, Collin P, Mäki M, Kaukinen K. Factors associated with long diagnostic delay in celiac disease. Scand J Gastroenterol. 2014;49(11):1304-1310. http://dx.doi.org/10.3109/00365521.2014.923502.

2. National Digestive Diseases Information Clearinghouse. Irritable bowel syndrome. 2013. http://digestive.niddk.nih.gov/ddiseases/pubs/ibs/. Accessed February 24, 2017.

3. El-Salhy M, Lomholt-Beck B, Gundersen D. The prevalence of celiac disease in patients with irritable bowel syndrome. Mol Med Rep. 2011;4(3):403-405. http://dx.doi.org/10.3892/mmr.2011.466.

4. Pironti A, Tadeu V, Pedroni A, et al. Role of routine small intestinal biopsy in adult patient with irritable bowel syndrome-like symptoms. Minerva Med. 2010;101(3):129-134.

5. Schuppan D, Zimmer KP. The diagnosis and treatment of celiac disease. Dtsch Ärztebl Int. 2013;110(49):835-846. http://dx.doi.org/10.3238/arztebl .2013.0835.

6. Strauch KA, Cotter VT. Celiac disease: an overview and management for primary care nurse practitioners. J Nurse Pract. 2011;7(7):588-599. http:// dx.doi.org/10.1016/j.nurpra.2011.03.003.

7. Carter SL, Attel S. The diagnosis and management of patients with lactoseintolerance. Nurse Pract. 2013;38(7):23-28. http://dx.doi.org/10.1097/01.NPR .0000429894 .03255 .80 .

8. Perets $\mathrm{TT}$, Shporn E, Aizic S, et al. A diagnostic approach to patients with suspected lactose malabsorption. Dig Dis Sci. 2014;59(5):1012-1016. http:// dx.doi.org/10.1007/s10620-013-2980-7.

9. Boettcher E, Crowe SE. Dietary proteins and functional gastrointestinal disorders. Am J Gastroentertol. 2013;108(5):728-736. http://dx.doi.org/10.1038/ ajg.2013.97.

10. Yang J, Deng $\mathrm{Y}$, Chu $\mathrm{H}$, et al. Prevalence and presentation of lactose intolerance and effects on dairy product intake in healthy subjects and patients with irritable bowel syndrome. Clin Gastroenterol Hepatol. 2013;11(3):262-268.e261. http://dx.doi.org/10.1016/j.cgh.2012.11.034.

11. Furnari $M$, Bonfanti $D$, Parodi $A$, et al. A comparison between lactose breath test and quick test on duodenal biopsies for diagnosing lactase deficiency in patients with self-reported lactose intolerance. J Clin Gastroenterol. 2013;47(2):148-152. http://dx.doi.org/10.1097/MCG.0b013e31824e9132.

12. Baffour-Awuah NY, Fleet S, Montgomery RK, et al. Functional significance of single nucleotide polymorphisms in the lactase gene in diverse US patients and evidence for a novel lactase persistence allele at 13909 in those of European ancestry. J Pediatr Gastroenterol Nutr. 2015;60(2): 182-191. http://dx.doi.org/10.1097/MPG.0000000000000595.

13. Gikas A, Triantafillidis JK. The role of primary care physicians in early diagnosis and treatment of chronic gastrointestinal diseases. Int J Gen Med. 2014;7:159-173. http://dx.doi.org/10.2147//JGM.S58888.

14. Tapia A, Hill AD, Ciarán KP, Calderwood AH, Murray JA. Diagnosis and management of celiac disease. Am J Gastroenterol. 2013;108:656-676. http:// dx.doi.org/10.1038/ajg.2013.79.

15. Yang J, Fox M, Cong Y, et al. Lactose intolerance in irritable bowel syndrome patients with diarrhoea: the roles of anxiety, activation of the innate mucosal immune system and visceral sensitivity. Aliment Pharmacol Ther. 2014;39(3): 302-311. http://dx.doi.org/10.1111/apt.12582.

16. Chapman TP, Chen LY, Leaver L. Investigating young adults with chronic diarrhoea in primary care. BMJ. 2015;350:h573. 1-4. http://dx.doi.org/10.1136/ bmj.h573.

17. Bakhshipour A, Nezam SK, Zakeri Z, Gharibi R, Bahari A, Kaykhaei MA. Coeliac disease in irritable bowel syndrome (ROME III) in southeast Iran. Arab J Gastroenterol. 2012;13(1):24-27. http://dx.doi.org/10.1016/j.ajg.2012 .03 .003 .

18. Tortora R, Imperatore N, Capone $\mathrm{P}$, et al. The presence of anti-endomysial antibodies and the level of anti-tissue transglutaminases can be used to diagnose adult coeliac disease without duodenal biopsy. Aliment Pharmacol Ther. 2014;40(10):1223-1229. http://dx.doi.org/10.1111/apt 12970 . 
19. Brookes L, Murray J. Diagnosing and managing celiac disease in primary care: application of current guidelines [interview transcript]. 2014. http://www.medscape.com/viewarticle/820397. Accessed February 24, 2017.

20. Rubio-Tapia A, Hill ID, Ciaran PK, et al. ACG clinical guidelines: diagnosis and management of celiac disease. Am J Gastroenterol. 2013;108(5):656-676. http://dx.doi.org/10.1038/ajg.2013.79.

21. Palsson OS, Whitehead WE, van Tilburg MA, et al. Rome IV diagnostic questionnaires and tables for investigators and clinicians. Gastroenterology. 2016. http://dx.doi.org/10.1053/j.gastro.2016.02.014.

22. Commonwealth Laboratories, LLC Diagnostic. 2016. https://ibschek.com/. Accessed February 24, 2017.

23. Pimentel M, Morales W, Rezaie A, et al. Development and validation of a biomarker for diarrhea-predominant irritable bowel syndrome in human subjects. PLoS One. 2015. http://dx.doi.org/10.1371/journal.pone.0126438. Accessed February 24, 2017.

24. Chira A, Dumitrascu DL. Serum biomarkers for irritable bowel syndrome. Clujul Med. 2015;88(3):258-264. http://dx.doi.org/10.15386/cjmed-496.
Karlen E. Luthy, DNP, FNP, is an associate professor at Brigham Young University in Provo, UT. She can be reached at beth_luthy@byu.edu. Sophia G. Larimer, MS, FNP, works at Valley Obstetrics \& Gynecology in Provo. Donna S. Freeborn, PhD, FNP, is an associate professor at Brigham Young University in Provo. In compliance with national ethical guidelines, the authors report no relationships with business or industry that would pose a conflict of interest.

$1555-4155 / 17 / \$$ see front matter

(c) 2017 Elsevier Inc. All rights reserved.

http://dx.doi.org/10.1016/j.nurpra.2017.01.018 